\title{
Ligand-Free Copper-Catalyzed Negishi Cross-Coupling
}

$$
\text { R-ZnX+ }
$$

$\mathrm{R}=$ Alk, Ar, alkynyl

$41-93 \%$ yield

$\mathrm{X}=\mathrm{Br}, \mathrm{Cl}$

\section{Selected examples:}<smiles>Clc1cc(NC2OCCCO2)ccn1</smiles>

$75 \%$ yield<smiles>c1ccc(N2CCCCC2)c(-c2cnccn2)c1</smiles>

$62 \%$ yield

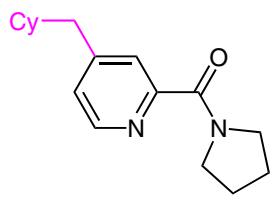

$53 \%$ yield

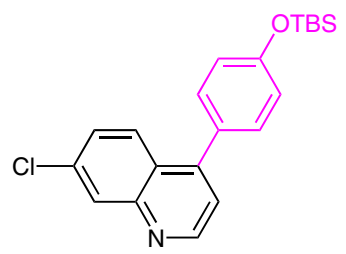

$57 \%$ yield<smiles>CCC(C)c1ccnc2cc(Cl)ccc12</smiles>

$73 \%$ yield

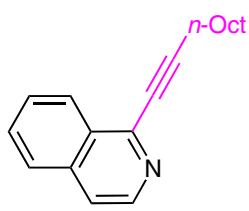

$45 \%$ yield

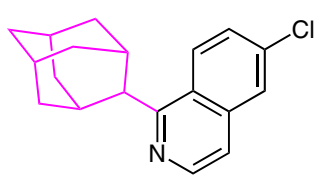

$76 \%$ yield

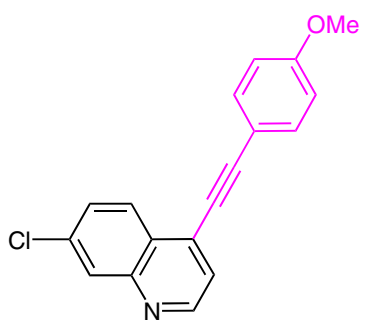

$45 \%$ yield
Significance: A ligand-free, copper-catalyzed Negishi cross-coupling of various zinc reagents with heteroaryl iodides affording the desired coupling products in very high yields is reported. The reaction proceeds within three hours at room temperature for alkylzinc reagents; however, higher temperatures are required for coupling with aryl- and alkynylzinc reagents.
Comment: Interestingly, no $\beta$-hydride elimination or rearrangement was observed for the coupling with primary, secondary, or tertiary alkylzinc reagents. Moreover, a variety of functional groups are tolerated in this protocol.

\section{Category}

Metal-Mediated

Synthesis

\section{Key words}

Negishi crosscoupling

copper

heteroaryls

Synfactu of the worn

SYNFACTS Contributors: Paul Knochel, Diana Haas 